\title{
The efficacy of an integrated intervention to encourage low- carbon travel behaviour
}

\author{
Yingying Jin ${ }^{1, *}$ \\ ${ }^{1}$ Zhejiang Academy of Culture \& Tourism Development, Tourism College of Zhejiang, China
}

\begin{abstract}
The importance of pro-environmental behaviour has increasingly attracted academics' attention. However, limited research has taken place to investigate the efficacy of different interventions on encouraging pro-environmental behaviour. The effects of an integrated intervention on changing people's actual travel behaviour also remain largely unfilled. Therefore, this empirical research aims to fill this research by examining the efficacy of an integrated intervention and its durability to encourage pro-environmental behaviour. SPSS programme was used to analyse the collected data: a primary online survey dataset and a secondary longitudinal dataset. The efficacy of the intervention was assessed using Kruskal-Wallis test and Wilcoxon Signed Ranks test was used to investigate the durability of its effectiveness.
\end{abstract}

\section{Introduction}

Behaviour change is not an event but a constantly changing process $[1,2]$. Prochaska and Velicer [3] identified that the change process consists of six phases: pre-contemplation, contemplation, preparation, action, maintenance, and termination. However, they have overlooked other influential factors such as habits and the availability of public infrastructures. Moreover, it simply assumes the existence of a direct causal relationship between intention and behaviour without explaining how such behaviour change occurs at different stages. In contrast, Geller's [4] flow of behaviour change provides a better explanation through the concept of competency. He opined that it is vital for intervention planer to evaluate whether the desired behaviour is performed and the frequency of its occurrence. This is to ensure that the desired behaviour has turned into a safe habit which can be difficult to change [4].

The efficacy of various behaviour change interventions has been researched in previous environmental studies [5,6], but much less attention has been devoted to the durability and effectiveness of integrated interventions. Although some researches have examined the efficacy of an integrated behaviour change intervention, yet its influence on the actual travel behaviour were not investigated [7].

Behaviour change interventions can be categorised as instructional, motivational and supportive. These three types of intervention target certain behavioural competence at different phases during the behaviour change process. When environmental destructive behaviours were performed unconsciously, instructional intervention can be used to give people instructions and rise their environmental awareness $[4,8]$. External factors could maximise the efficacy of motivational and supportive interventions to encourage even more proenvironmental behaviour $[4,9]$. The market survey of Corporate Culture revealed that $77 \%$ of the organisations were using instructional interventions while $24 \%$ of them used motivational interventions such as incentives and penalties, not to mention the lack of use of both supportive and integrated interventions [10]. For the purpose of this study, the following sections will briefly introduce a small selection of motivational and supportive initiatives.

\subsection{Motivational interventions}

Motivational interventions such as incentives and disincentives come in effect when people do not do what they know [4]. The public sector has a great tendency to use disincentives and penalties in forms of laws or ordinances such as fines to motivate pro-environmental behaviours $[4,9,8]$. However, these initiatives have been criticised by many researchers due to its negative effects $[11,12]$. Greenredeem also found that only $6 \%$ of the UK residents acknowledge fines could positively affect their pro-environmental behaviour, but a majority of them suggest that it can be demotivating [5].

Incentives are usually provided when the desired behaviour is performed or a particular outcome is achieved [4]. It can be divided into monetary and nonmonetary incentives such as discounts, recognition, verbal commendations, and monetary rebates. Monetary incentive could be adopted when cost is the main drawback for engaging in pro-environmental behaviour. The experimental research done by the Eden Project and others has also demonstrated that financial reward could increase green purchase behaviours [7]. Non-monetary incentive is to motivate people through recognition and praise [13]. However, both monetary and non-monetary incentives only have short-lived effects in condition of the

\footnotetext{
* Corresponding author: jin_yingying18@163.com
} 
incentives are in place as they can hardly generate much intrinsic change on people's behaviour [9]. Accordingly, a combination of both motivational and supportive interventions for a long-term implementation is urged to turn the desired behaviour into a good habit.

\subsection{Supportive interventions}

Supportive intervention such as benchmarking and feedback could be effective when people already do what they know, as it could encourage them to practice these behaviours pro-actively until they are being practiced as an automatic habitual behaviour [4]. When developing feedback techniques, the key challenge is how to design "one-size-fits-all" feedback to cater for individuals that are driven by different motivations [6]. Nonetheless, although personalised feedback is advised to be helpful when encouraging pro-environmental behaviour change, the feedback must be specific and authoritative. Accordingly, feedback provided by an independent organisation is preferred as it is more trustful, so that the public would believe no commercial interest is involved [7].

When design supportive intervention, social norms can be formed and strengthened using two kinds of benchmark feedbacks which are injunctive message and descriptive normative information [14]. Injunctive messages are information which are either socially approved or disapproved, descriptive normative information provides a rate that reflects the extent to which a particular behaviour is perceived to be common [15]. Cialdini et al. state that descriptive normative information could decrease households' energy intensive consumption. Nonetheless, negative boomerang effect could occur for those who were already low in energy consumption, such effect could be buffered by adding injunctive message [15]. When using widely spread social norms campaigns, it is important to make sure that both environmental and non-environmental individuals could receive the message [14].

From the literature review, it is clear that no intervention could be effect when working on its own. An integration of both motivational and supportive interventions is needed to maximum their effects. However, the empirical research gap on the durability of their effectiveness on encouraging pro-environmental travel behaviour remains. Therefore, this research aims to examine weather an integrated intervention can or cannot change people's actual travel behaviour and sustain its effect.

\section{Materials and Methods}

Eco Rewards scheme integrates both motivational and supportive interventions by providing financial reward for its members who continuously travel using eco-friendly transport modes. The scheme has been operated for the period of 54 weeks prior to data analysis. A point system is used to record individual member's travel performance. Their members can not only exchange the points for cashback, free offers, and discounted products from more than
2000 cooperative retailers, a weekly feedback is also provided based on their green behaviours such as the amount of $\mathrm{CO} 2$ emissions saved as a result of their green journeys. This research examines the effectiveness of this scheme on encouraging environmentally friendly travel behaviours.

This research is part of a larger study [16] wherein both a primary online survey dataset and a secondary longitudinal dataset were collected. Self-selection sampling was used to select participants for partaking in primary survey. They were approached by the collaborating organisation on behalf of the researcher. Research invitation was sent through emails. The longitudinal dataset was carefully selected to be consistent with the participants partake in the primary survey. This helps the researcher to better examine the relationship between participants' attitude and their actual travel behaviour, as well as the effectiveness of the scheme on changing and maintaining their travel behaviour. SPSS programme and non-parametric measure were used to analyse both datasets because the longitudinal data was abnormally distributed.

\section{Results \& Discussion}

Kruskal-Wallis test was adopted to assess the effectiveness of the intervention scheme by comparing participants' travel behaviour before and after joining the scheme, as well as their short- and mid-term effects. The level of significance of participants' different travel behaviours during weekdays between before- and afterjoin were all below 0.05. Participation in green travel (i.e., walking and cycling) and public transport were increased most significantly, which counted for 0.001 and 0.003 , respectively. Changes in car travel being the least significant with a significance level of 0.039 . Accordingly, after joining the scheme, participants' travel behaviours changed significantly, they travelled more frequently using same travel modes as they used to be. These behaviours would become habits as a result of relatively fixed schedules during weekdays. In contrast, during weekends, the scheme has significant effects only on public transport travel (0.001), while green travel (0.797) and car travel behaviours $(0.460)$ remain unchanged. This contradiction in the effectiveness of the scheme might due to the difference in travel purposes. The findings revealed that for daily commute most participants would take public transport, but for grocery shopping, visiting friends and relatives, leisure activities, and domestic holidays, car travel is preferred. Accordingly, there is a negative contextual spill over exists $[17,2,18]$.

Furthermore, Wilcoxon Signed Ranks test was used to examine the durability of the scheme's effectiveness. As illustrated in Table 1, the effectiveness of the scheme between 'short-term' and 'long-term' are significantly different $(\mathrm{p}<0.05)$ in pairs other than the pair 5,6,8, and 9 as they $\mathrm{p}$-value are all greater than 0.05 . After joining the scheme, green travellers (pair 1) increased their participation in green travel modes during the 'mid-term', while participants who typically travel with public transport (pair 4) and travel by car (pair 7) have increased 
their existing travel behaviour in 'short-term' (the effect sizes of both pairs were 0.51). Based on the findings, the effectiveness of the Eco Rewards scheme on sustaining their members' travel behaviour is proven to be successful.
It also demonstrates that habitual behaviour can be changed and transformed into pro-environmental travel behaviour by using interventions $[19,20]$.

Table 1 The short-term and mid-term effectiveness of the scheme on different travel behaviours

\begin{tabular}{|c|c|c|c|c|c|c|c|c|}
\hline & \multicolumn{4}{|c|}{ Ranks } & \multicolumn{2}{|c|}{ Test Statistics } & \multirow{2}{*}{$\begin{array}{c}\begin{array}{c}\text { Effect size } \\
\text { statistic }\end{array} \\
\mathrm{R} \\
\end{array}$} \\
\hline & & & $\mathrm{N}$ & $\begin{array}{l}\text { Mean } \\
\text { Rank }\end{array}$ & $\begin{array}{l}\text { Sum of } \\
\text { Ranks }\end{array}$ & $Z$ & $\begin{array}{c}\text { Asymp. Sig. } \\
\text { (2-tailed) }\end{array}$ & \\
\hline $\begin{array}{l}\text { Pair } \\
1\end{array}$ & $\begin{array}{l}\text { Mid-term (Total no. of green } \\
\text { travel) - Short term (Total no. of } \\
\text { green travel) }\end{array}$ & $\begin{array}{l}\text { Negative Ranks } \\
\text { Positive Ranks } \\
\text { Tie }\end{array}$ & $\begin{array}{c}7 \\
24 \\
4\end{array}$ & $\begin{array}{l}18.93 \\
15.15\end{array}$ & $\begin{array}{l}132.50 \\
363.50\end{array}$ & $\begin{array}{c}- \\
2.265\end{array}$ & .024 & \\
\hline $\begin{array}{l}\text { Pair } \\
2\end{array}$ & $\begin{array}{l}\text { Mid-term (Total no. of public } \\
\text { transport) - Short term (Total no. } \\
\text { of green travel) }\end{array}$ & $\begin{array}{l}\text { Negative Ranks } \\
\text { Positive Ranks } \\
\text { Ties }\end{array}$ & $\begin{array}{c}30 \\
3 \\
2\end{array}$ & $\begin{array}{l}16.65 \\
20.50\end{array}$ & $\begin{array}{c}499.50 \\
61.50\end{array}$ & $\begin{array}{c}- \\
3.914\end{array}$ & .000 & .47 \\
\hline $\begin{array}{l}\text { Pair } \\
3\end{array}$ & $\begin{array}{l}\text { Mid-term (Total no. of car } \\
\text { travel) - Short term (Total no. of } \\
\text { green travel) }\end{array}$ & $\begin{array}{l}\text { Negative Ranks } \\
\text { Positive Ranks } \\
\text { Ties }\end{array}$ & $\begin{array}{c}27 \\
5 \\
3\end{array}$ & $\begin{array}{c}17.74 \\
9.80\end{array}$ & $\begin{array}{c}479.00 \\
49.00\end{array}$ & $\begin{array}{c}- \\
4.021\end{array}$ & .000 & .48 \\
\hline $\begin{array}{l}\text { Pair } \\
4\end{array}$ & $\begin{array}{l}\text { Mid-term (Total no. of green } \\
\text { travel) - Short term (Total no. of } \\
\text { public transport) }\end{array}$ & $\begin{array}{l}\text { Negative Ranks } \\
\text { Positive Ranks } \\
\text { Ties }\end{array}$ & $\begin{array}{c}3 \\
30 \\
2\end{array}$ & $\begin{array}{l}14.00 \\
17.30\end{array}$ & $\begin{array}{c}42.00 \\
519.00\end{array}$ & -4.262 & .000 & .51 \\
\hline $\begin{array}{l}\text { Pair } \\
5\end{array}$ & $\begin{array}{l}\text { Mid-term (Total no. of public } \\
\text { transport) - Short term (Total no. } \\
\text { of public transport) }\end{array}$ & $\begin{array}{l}\text { Negative Ranks } \\
\text { Positive Ranks } \\
\text { Ties }\end{array}$ & $\begin{array}{c}2 \\
3 \\
30\end{array}$ & $\begin{array}{l}3.00 \\
3.00\end{array}$ & $\begin{array}{l}6.00 \\
9.00\end{array}$ & -.412 & .680 & .05 \\
\hline $\begin{array}{l}\text { Pair } \\
6\end{array}$ & $\begin{array}{l}\text { Mid-term (Total no. of car travel) } \\
\text { - Short term (Total no. of public } \\
\text { transport) }\end{array}$ & $\begin{array}{l}\text { Negative Ranks } \\
\text { Positive Ranks } \\
\text { Ties }\end{array}$ & $\begin{array}{c}4 \\
13 \\
18\end{array}$ & $\begin{array}{c}12.25 \\
8.00\end{array}$ & $\begin{array}{c}49.00 \\
104.00\end{array}$ & -1.305 & .192 & .16 \\
\hline $\begin{array}{l}\text { Pair } \\
7\end{array}$ & $\begin{array}{l}\text { Mid-term (Total no. of green } \\
\text { travel) - Short term (Total no. of } \\
\text { car travel) }\end{array}$ & $\begin{array}{l}\text { Negative Ranks } \\
\text { Positive Ranks } \\
\text { Ties }\end{array}$ & $\begin{array}{c}6 \\
28 \\
1\end{array}$ & $\begin{array}{c}8.08 \\
19.52\end{array}$ & $\begin{array}{c}48.50 \\
546.50\end{array}$ & -4.257 & .000 & .51 \\
\hline $\begin{array}{l}\text { Pair } \\
8\end{array}$ & $\begin{array}{l}\text { Mid-term (Total no. of public } \\
\text { transport) - Short term (Total no. } \\
\text { of car travel) }\end{array}$ & $\begin{array}{l}\text { Negative Ranks } \\
\text { Positive Ranks } \\
\text { Ties }\end{array}$ & $\begin{array}{c}13 \\
3 \\
19\end{array}$ & $\begin{array}{c}7.31 \\
13.67\end{array}$ & $\begin{array}{l}95.00 \\
41.00\end{array}$ & -1.398 & .162 & .17 \\
\hline $\begin{array}{l}\text { Pair } \\
9\end{array}$ & $\begin{array}{l}\text { Mid-term (Total no. of car travel) } \\
\text { - Short term (Total no. of car } \\
\text { travel) }\end{array}$ & $\begin{array}{l}\text { Negative Ranks } \\
\text { Positive Ranks } \\
\text { Ties }\end{array}$ & $\begin{array}{c}9 \\
8 \\
18\end{array}$ & $\begin{array}{c}8.00 \\
10.13\end{array}$ & $\begin{array}{l}72.00 \\
81.00\end{array}$ & -.214 & .830 & .03 \\
\hline
\end{tabular}

Source: Authors' calculations based on secondary longitudinal data.

The success of this scheme might due to its accurately focus on the most influential factors: convenience and cost. The findings shows that over $49 \%$ of participants joining the scheme were motivated by its financial benefits, environmental concern or commitment were counted for only $14.6 \%$. The effectiveness is also demonstrated through their changing behaviour after joining the scheme, as some participants stated:

"It felt like I was getting rewarded for making travel choices which are easing congestion and good for the environment too".

"It was a healthy and pra[c]tical option and I am getting paid at the same time".

These extracts revealed the importance of the incentive-based intervention when motivating participants' involvement in the scheme. Such importance was also illustrated in their recommendation for improving the intervention, as to create a better reward system and to provide a clearer instruction on claiming the rewards were most mentioned. However, some researchers $[4,9]$ state that as soon as the incentive is gone its effect will be faded. This is also mentioned by one participant who suggested that:

"I'd move the [title of the] scheme away from 'rewards' to positive reinforcement about the travel choices people are making."

"The apps 'Plant Nanny' and 'Walkr' are good examples of encouraging people to change habits in a fun informative way without any tangible benefits except for associated health benefits."

Another potential reason for the success of this scheme might due to its integrative nature being both incentive- and information-based interventions. As some participants mentioned that both incentive and feedback are their main motivation factors to join the scheme:

"Interested in knowing how much money and CO2 I am saving by cycling/car sharing".

"The information that I receive and also the benefits that I have when shopping".

"To record my travel choices and be rewarded for my economic friendly choices". 


\section{Conclusions}

This study found that the effectiveness of an integrated intervention on changing people's travel behaviour and sustaining the effects to be valid. Nonetheless, the level of significance various across different travel behaviours. For instance, during weekdays, green travelers have a greater tendency to maintain their routinised daily commute behaviour, while people who regularly travel by public transport and car had more green travel behaviours in 'mid-term'. However, during weekends, participants would travel more by taking public transport and car for leisure purposes. Although this study has examined the efficacy of the integrative intervention, it overlooks its post-scheme effects due to the constraints of time. This would be a interesting area for future research by investigating the influence of the scheme on those who have been dropped-out or current participants' postscheme travel behaviour.

Despite the success of the scheme on changing people's travel behaviour, there are some potential areas for improvement in the intervention. For the intervention developer, they could enhance their current system by providing explicit information on its purpose with a stepto-step guide on the participation process. This is because in contrast with other similar interventions which focus on financial incentives, the economic rewards in this scheme are relatively small and unattractive. Moreover, the reward claiming process are extremely time consuming which needs to be more user-friendly. Furthermore, the use of smart technologies such as mobile applications by proving more personalised benchmarking information on participants' travel behaviour is recommended as it appears to be more attractive for users.

\section{Reference}

1. N. Carr, "Going with the flow: An assessment of the relationship between young people's leisure and holiday behaviour," Tourism Geographies, vol. 4, no. 2, pp. 115-134, 2002.

2. S. Böhler, S. Grischkat, S. Haustein and M. Hunecke, "Encouraging environmentally sustainable holiday travel," Transportation Research Part A: Policy and Practice, vol. 40, no. 8, pp. 652-670, 2006.

3. J. Prochaska and W. Velicer, "The Transtheoretical Model of Health Behavior Change," American Journal of Health Promotion, vol. 12, no. 1, pp. 3848, 1997.

4. E. Geller, "The challenge of increasing proenvironment behavior," in Handbook of environmental psychology, New York, NY, Wiley, 2002, p. 525-540.

5. Greenredeem, "Rewards \& recycling: How incentives may have the answer for a 'zero waste economy' in the UK.," Greenredeem, Ipswich, 2013.
6. H. He, S. Greenberg and E. E. M. E. Huang, "One size does not fit all: applying the transtheoretical model to energy feedback technology design," in Proceedings of the SIGCHI Conference on Human Factors in Computing Systems, Atlanta: ACM, 2010.

7. The Eden Project, Homebase, Acona, Resolve,University of Plymouth, "Home front: the 21 st century living project report," The Eden Project, Bodelva, 2009.

8. M. Falk and E. Hagsten, "Short-run impact of the flight departure tax on air travel," International Journal of Tourism Research, no. March, pp. 1-8, 2018.

9. L. Steg and C. Vlek, "Encouraging proenvironmental behaviour: An integrative review and research agenda," Journal of Environmental Psychology, vol. 29, no. 3, p. 309-317, 2009.

10. Corporate Culture, "Motivating millions," Corporate Culture, London, 2013.

11. Keep Britain Tidy, "The Effectiveness of Enforcement on Behaviour Change: Fixed penalty notices from both sides of the line," Keep Britain Tidy, Wigan, 2011.

12. F. Scrimgeour, L. Oxley and K. Fatai, "Reducing carbon emissions? The relative effectiveness of different types of environmental tax: the case of New Zealand," Environmental Modelling \& Software, vol. 20, no. 11, p. 1439-1448, 2005.

13. N. Govindarajulu and B. Daily, "Motivating employees for environmental improvement," Industrial Management \& Data Systems, vol. 104, no. 4, p. 364-372, 2004.

14. P. Schultz, J. Nolan, R. Cialdini, N. Goldstein and V. Griskevicius, "The constructive, destructive, and reconstructive power of social norms. ", Psychological Science, vol. 18, no. 5, p. 429-434, 2007.

15. R. Cialdini, C. Kallgren and R. Reno, "A focus theory of normative conduct: A theoretical refinement and reevaluation of the role of norms in human behavior," Advances in Experimental Social Psychology, vol. 24, no. 20, pp. 1-243, 1991.

16. Y. Jin, "Dissertation: An exploration into the effect of different tools on encouraging pro-environmental behaviour," University of Surrey, Guildford , 2015.

17. T. Gärling and K. Axhausen, "Introduction: Habitual travel choice," Transportation, vol. 30, no. 1, pp. 1$11,2003$.

18. S. Barr, G. Shaw, T. Coles and J. Prillwitz, "A holiday is a holiday': practicing sustainability, home and away," Journal of Transport Geography, vol. 18 , p. $474-481,2010$. 
19. J. Garvill, A. Marell and A. Nordlund, "Effects of increased awareness on choice of travel mode," Transportation, vol. 30, no. 1, p. 63-79, 2003.

20. S. Fujii and R. Kitamura, "What does a one-month free bus ticket do to habitual drivers? An experimental analysis of habit and attitude change," Transportation, vol. 30, no. 1, pp. 81-95, 2003. 